\title{
Transvenous Embolization of Dural Carotid Cavernous Fistula through the Supraorbital Vein
}

\author{
Woong Han, Jae Hoon Kim, Hee In Kang, Deok Ryeong Kim, Byung Gwan Moon, Joo Seung Kim \\ Department of Neurosurgery, Eulji University Eulji Hospital, Seoul, Korea
}

We describe a case of transvenous embolization through the dilated supraorbital vein to treat a dural carotid cavernous fistula. The approach through the common facial vein or direct access of the superior ophthalmic vein is a commonly used route to the superior ophthalmic vein when the approach via the inferior petrosal sinus is unavailable. In rare cases, the dilated supraorbital vein provides an alternative route and we discuss the technical details.

Keywords dural carotid cavernous fistula, supraorbital vein, transvenous embolization

\author{
J Cerebrovasc Endovasc Neurosurg. \\ 2019 June;21(2):101-106 \\ Received : 29 May 2019 \\ Revised : 18 June 2019 \\ Accepted : 20 June 2019
}

Correspondence to Jae Hoon Kim Department of Neurosurgery, Eulji University Eulji Hospital, 68, Hangeulbiseok-ro, Nowon-gu, Seoul 01830, Korea

\author{
Tel : 02-970-8267 \\ Fax : 02-979-8268 \\ E-mail : grimi2@hanmail.net \\ ORCID : http://orcid.org/0000-0002-9179-8569
}

This is an Open Access article distributed under the terms of the Creative Commons Attribution NonCommercial License /http://creativecommons.org/licenses/by-nc/3.0) which permits unrestricted noncommercial use, distribution, and reproduction in any medium, provided the original work is properly cited.

\section{INTRODUCTION}

A dural carotid cavernous fistula (dCCF) is an abnormal communication between branches of the external or internal carotid artery and a vein drained to the cavernous sinus (CS). It usually occurs spontaneously and its pathogenesis is unknown. However, we assume it is associated with the CS thrombosis. ${ }^{1)}$

The goal of dCCF treatment is to obliterate abnormal shunts and decrease the pressure in the CS when progressive ocular symptoms and retrograde cortical venous drainage are persistent. The current treatment of choice is transvenous embolization (TVE) with detachable coils or embolic materials. The most commonly used route to the CS is the inferior petrosal sinus." Alternative route include the pterygoid plexus, the superior petrosal sinus, the common facial vein, and direct access of the superior ophthalmic vein. ${ }^{41012) 133}$ In addition, the dilated supraorbital vein provides an alternative route to the superior ophthalmic vein but is rarely reported. ${ }^{25) 111}$

We present a case of TVE through the dilated supraorbital vein and discuss its technical details.

\section{CASE REPORT}

A 55-year-old woman suffered from progressive visual loss, chemosis, and exophthalmos in her left eye. Engorgement of the left ophthalmic vein and proptosis were identified on the computed tomographic scan (Fig. 1A). Cerebral angiography indicated a left dCCF fed by branches of the left external and internal carotid artery and drained exclusively into the superior ophthalmic vein, the angular vein, and the supraorbital vein (Fig. 1B, C).

The patient was premedicated with acetylsalicylic 
acid (100 mg) and clopidogrel $(75 \mathrm{mg})$, starting 5 days before the procedure. The TVE was performed under general anesthesia. During the procedure, we placed a $5 \mathrm{~F}$ sheath in the right femoral artery and a $6 \mathrm{~F}$ sheath in the right femoral vein. We first approached via the inferior petrosal sinus. A $6 \mathrm{~F}$ Envoy catheter (Cordis, Miami Lakes, FL) was advanced to the level of the junction of the internal jugular vein and the sigmoid sinus. Using an Excelsior 1018 microcatheter (Stryker, Kalamazoo, MI), we selected the inferior pet-
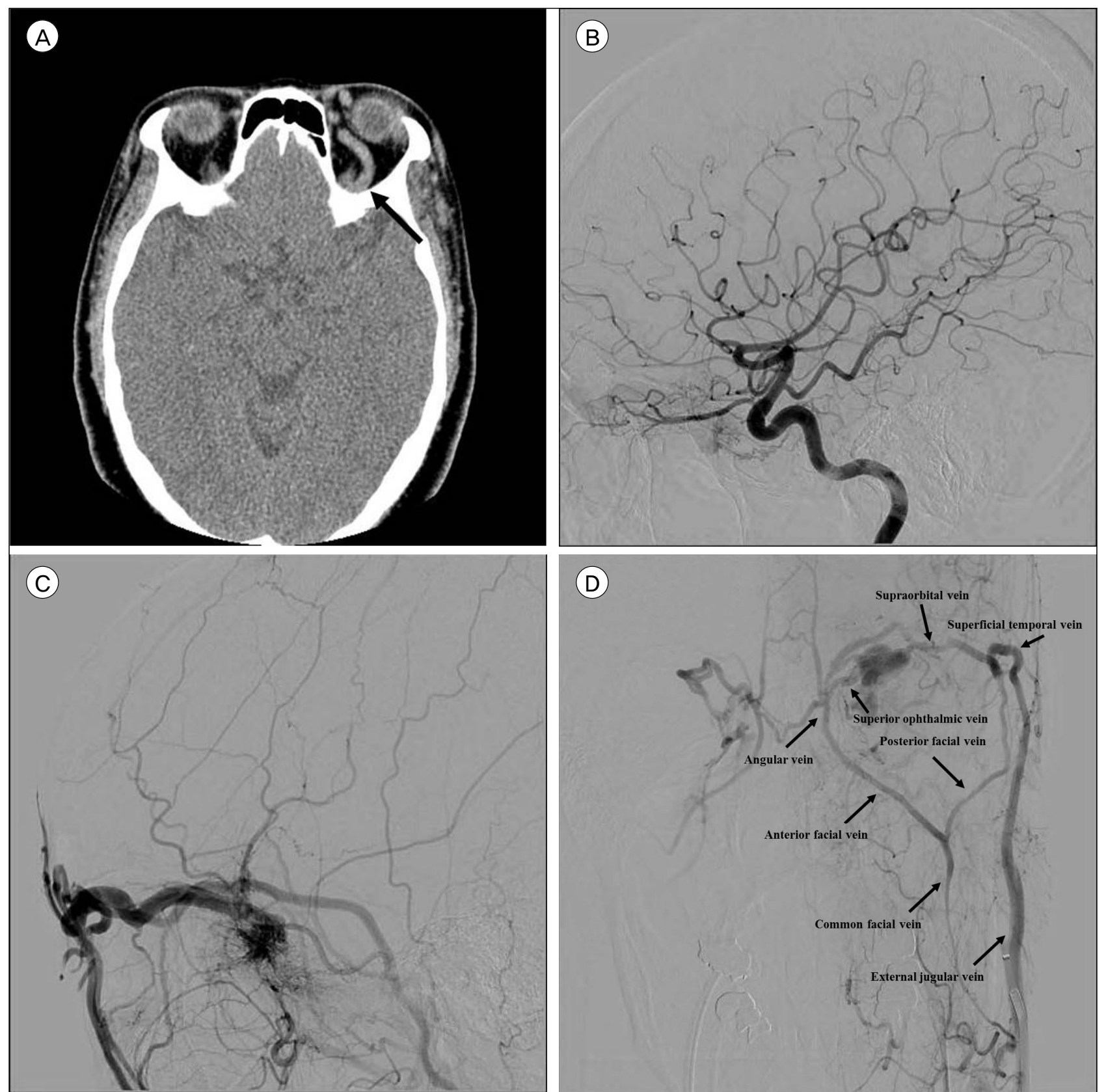

(D)

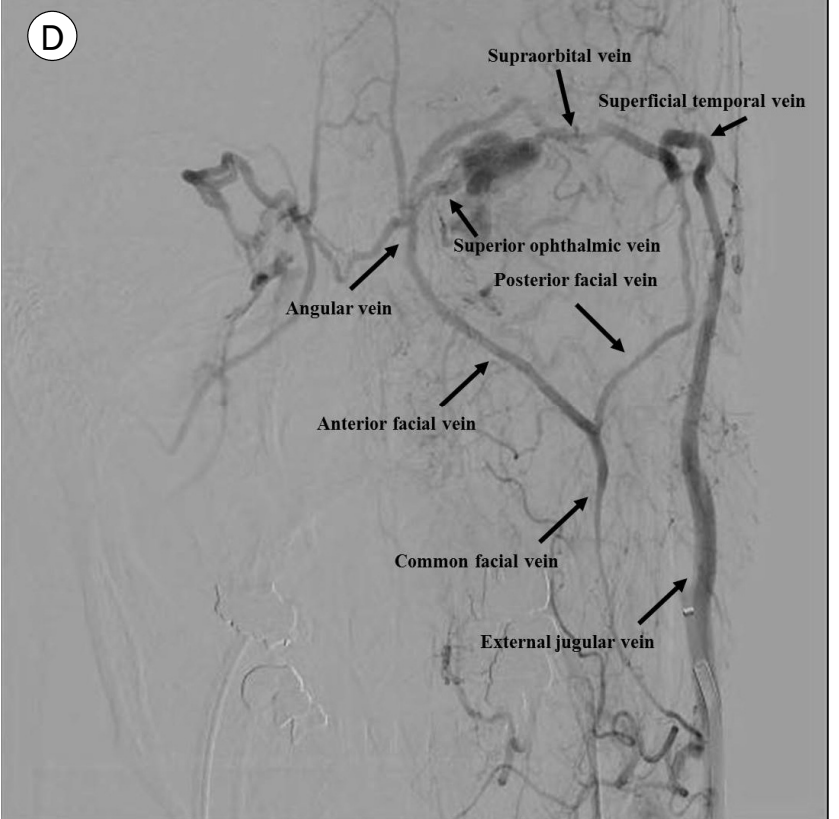

Fig. 1. (A) Brain computed tomographic scan showing proptosis of the left eye ball and engorged left superior ophthalmic vein (arrow). ( $\mathrm{B}, \mathrm{C}$ ) Left internal carotid artery and external carotid artery angiogram showing a dural carotid cavernous fistula fed by branches of the left internal carotid artery and branches of the deep temporal artery and the internal maxillary artery drained into the cavernous sinus, the superior ophthalmic vein, the common facial vein, the suprorbital vein and the external jugular vein, subsequently. (D) Venous phase of the left external carotid artery angiogram showing the venous architecture of the presented case. 
rosal sinus and advanced the microcatheter tip to the CS. However, we could not access the superior ophthalmic vein through the CS due to intracavernous septations. Instead, we attempted to navigate the microcatheter through the common facial vein, but failed due to severe tortuosity and segmental stenosis. We decided to approach via the dilated supraorbital vein and exchanged the $6 \mathrm{~F}$ femoral sheath to a $7 \mathrm{~F}$ sheath in the right femoral vein. We placed the 7F Envoy catheter at the junction of the supraorbital vein and the frontal branch of the superficial temporal vein. We failed to navigate Excelsior 1018 microcatheter
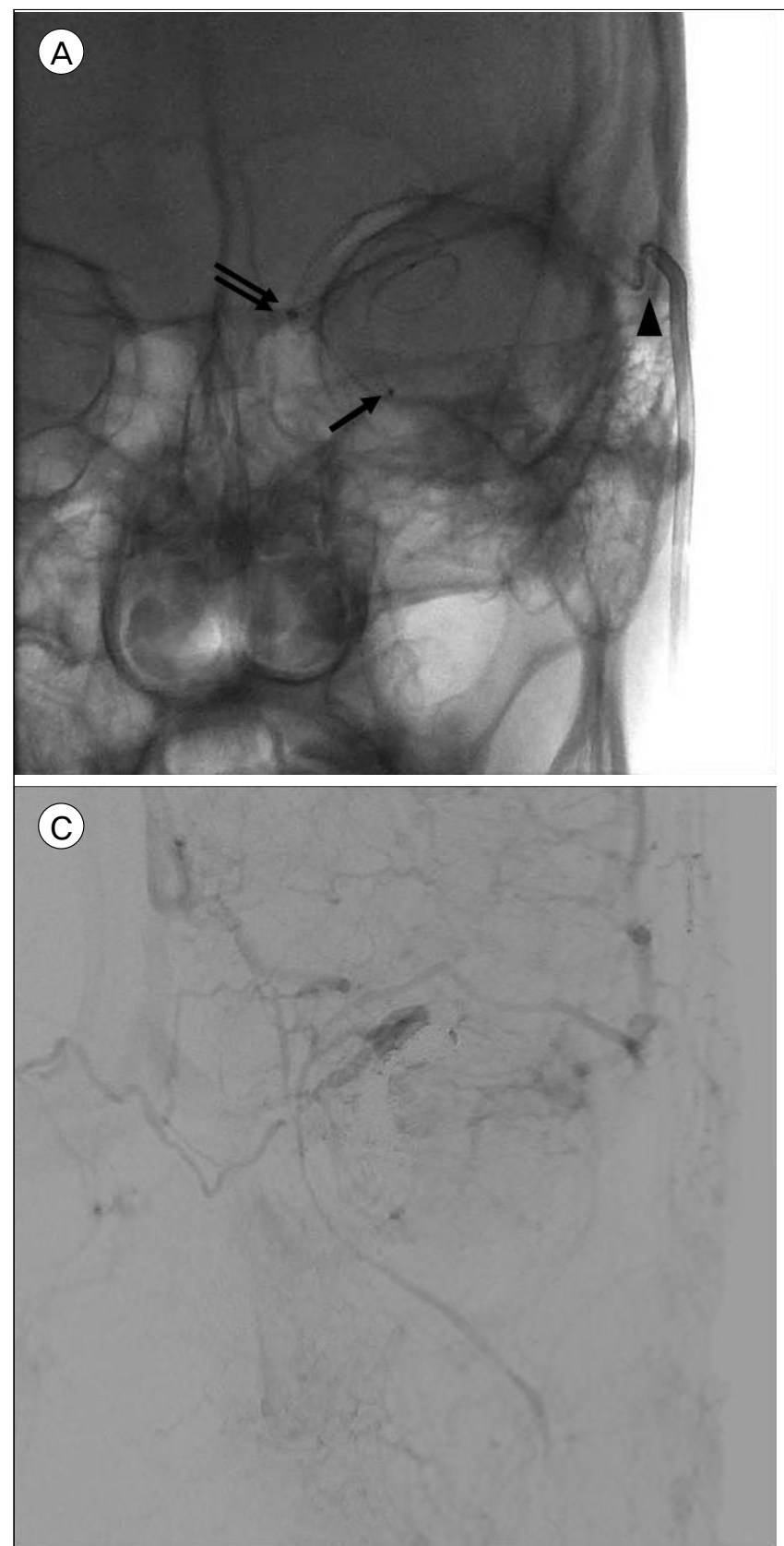

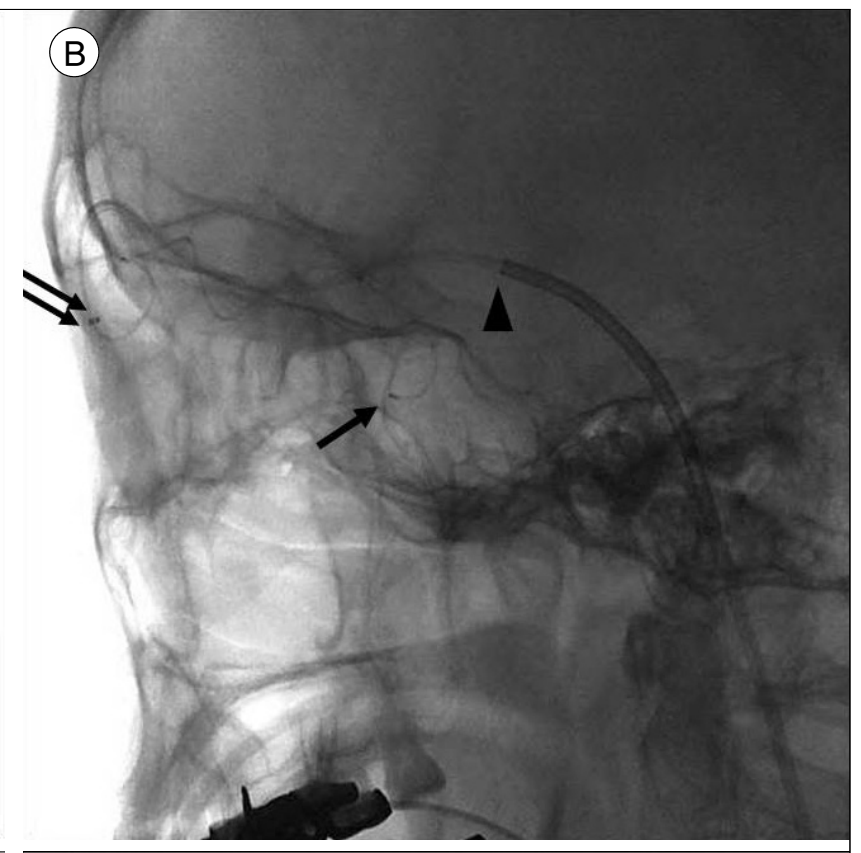

(D)

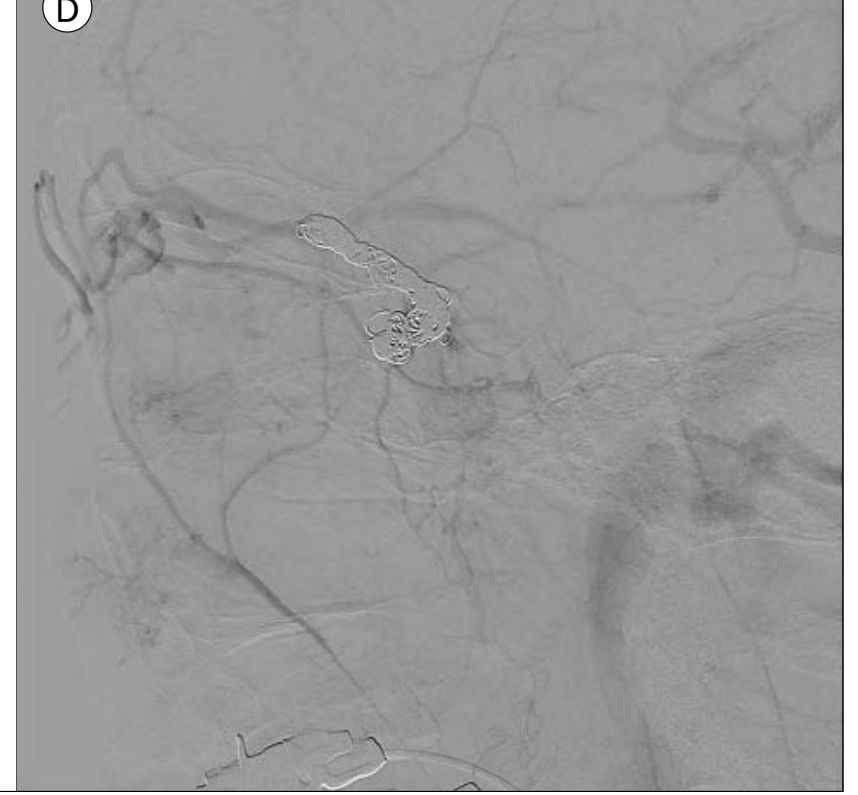

Fig. 2. (A, B) Plain x-rays showing a microcatheter (single arrow) within the cavernous sinus, a distal access catheter (double arrow) at the junction of the supraorbital vein and the angular vein, and a guiding catheter (arrow head) at the junction of the supraorbital vein and the frontal branch of the superficial temporal vein. (C, D) Immediate post-embolization angiogram of the left external carotid artery showing subtotal occlusion of the dural carotid cavernous fistula. 
through the supraorbital vein due to its rigid profile and thus exchanged the Excelsior 1018 microcatheter to Prowler 14 microcatheter (Cordis, Miami Lakes, FL). We successfully navigated the Prowler 14 microcatheter via the dilated supraorbital vein supported by a $5 \mathrm{~F}$ Sofia distal access catheter (Microvention, Tustin, CA) and could access the superior ophthalmic vein and embolized the dCCF with detachable coils (Fig. 2A, B). Immediate post-embolization angiography showed subtotal occlusion of the dCCF (Fig. $2 \mathrm{C}, \mathrm{D})$. The patient's visual acuity improved and intraocular pressure was normalized after the procedure. A follow-up angiogram at 3 months showed a small fistula fed by the middle meningeal

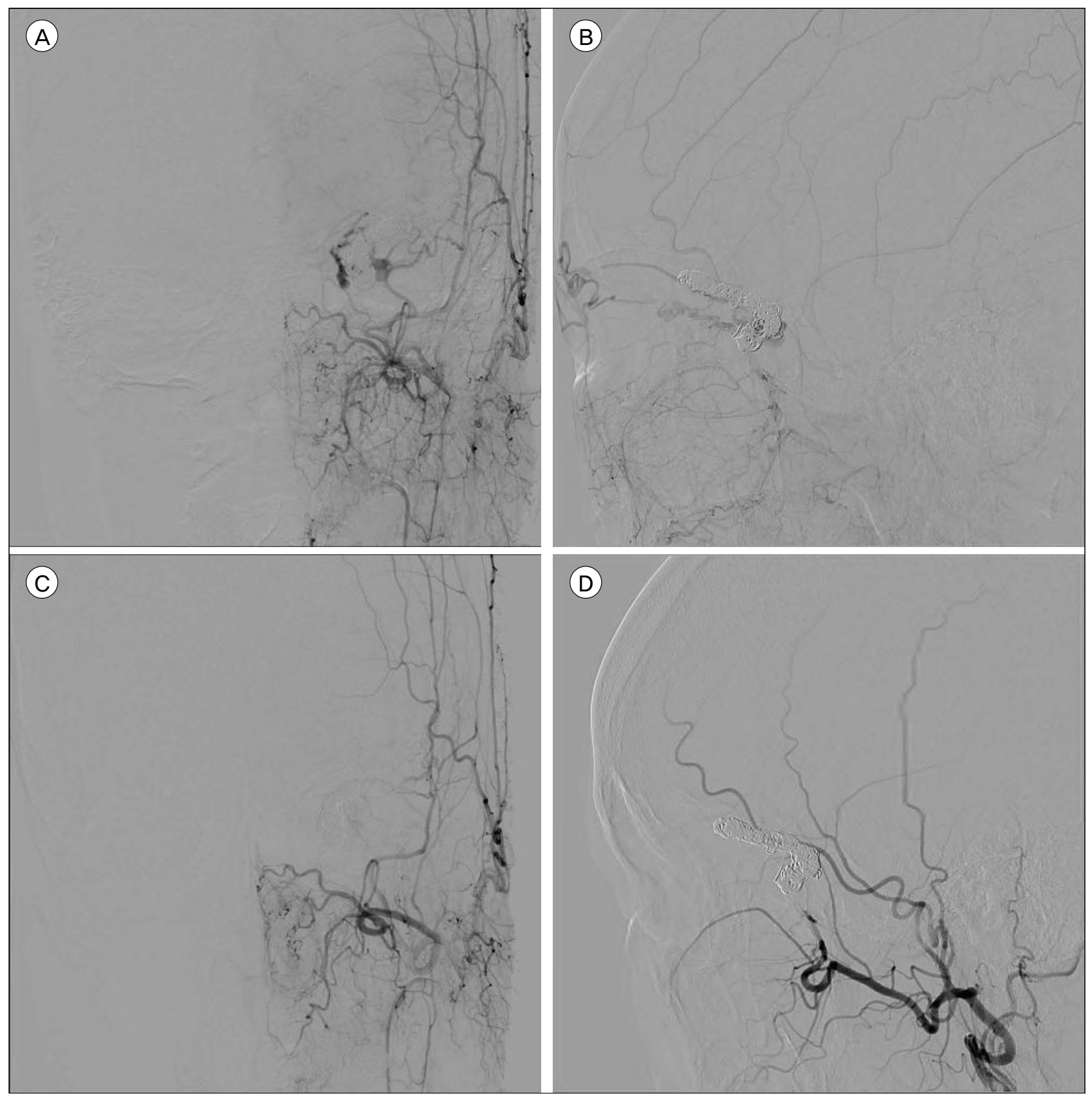

Fig. 3. (A, B) Left external carotid artery angiogram after 3 months showing small fistula fed by the middle meningeal artery. (C, D) Left external carotid artery angiogram after 8 months showing a complete occlusion of dural carotid cavernous fistula. 
artery and a subsequent angiogram at 8 months demonstrated complete occlusion of the dCCF (Fig. 3A-D).

\section{DISCUSSION}

Treatment of a dCCF is mandatory when the visual function is progressively compromised. Because $\mathrm{dCCF}$ often have multiple small feeders from the external or internal carotid artery, TVE is usually preferred. The transvenous route through the inferior petrosal sinus is commonly used due to its short connection to the CS. If the inferior petrosal sinus route is not accessible, the anterior transfacial route to the CS through the superior ophthalmic vein is an alternative.

The transfacial approach through the common facial vein or the supraorbital vein is time-consuming and technically challenging. The major problem is the microcatheter navigation across a long and tortuous vein to the superior ophthalmic vein. The common facial vein or the angular vein sometimes is tortuous and its acute curvature toward the orbit prevents to access to the superior ophthalmic vein. In particular, the microcatheter navigation across the supraorbital vein through the frontal branch of the superficial temporal vein has tortuous and long passage. Therefore, it is necessary to position a guiding catheter as distally as possible for robust support. In this case, we coaxially advanced a distal access catheter (5F Sofia) with a guiding catheter (7F Envoy) and placed a distal access catheter at the junction of the supraorbital vein and the angular vein and a guiding catheter at the junction of the supraorbital vein and the frontal branch of the superficial temporal vein, respectively. Also, it is important to choose a microcatheter with a soft tip profile. To the best of our knowledge, the TVE of $\mathrm{dCCF}$ through the supraorbital vein has been reported only three cases in the literature. ${ }^{2) 5(11)}$

Another important factor for successful transfacial access to the CS is a thorough understanding of facial venous anatomy. The superior ophthalmic vein is formed by the joining of two veins, the supraorbital and angular vein at the superomedial orbital rim. ${ }^{6}$ The angular vein connects with the facial vein and drains into the internal jugular vein. The supraorbital vein superiorly connects with the supratrochlear vein and laterally communicates with the frontal branch of the superficial temporal vein, which drains into the external jugular vein. ${ }^{6}$ ) There was a rare anatomical variation of the venous system in this case. The common facial vein was communicated with the external jugular vein, not the internal jugular vein. Therefore, the external jugular vein had a relatively large caliber allowing a 7F guiding catheter to be advanced into the superficial temporal vein. The venous architecture of the presented case is illustrated in Fig. 1D. Preoperative venous phase angiograms and an intraoperative venous road map may help to find a relevant venous route.

Although recent studies reported higher dCCF occlusion rates with liquid embolic materials than with coils alone and durable mid- and long-term results, treatment with liquid embolic agent may result in the occlusion of arterial collaterals and cause cranial nerve ischemia. ${ }^{3778)}$ In this case, we did not use any embolic materials to achieve complete occlusion because small feeders from the branches of the internal carotid artery may be compromised.

\section{CONCLUSIONS}

The TVE of a dCCF via a dilated supraorbital vein provides an alternative route when other transvenous routes are unavailable.

\section{REFERENCES}

1. Aboian MS, Daniels DJ, Rammos SK, Pozzati E, Lanzino. The putative role of the venous system in the genesis of vascular malformations. Neurosurg Focus. 2009 Nov;27(5):E9.

2. Agid R, Willinsky RA, Haw C, Souza MP, Vanek IJ, TerBrugge KG. Targeted compartmental embolization of cavernous sinus dural arteriovenous fistulae using transfemoral medial and lateral facial vein approaches. Neuroradiolgy. 2004 Feb;46(2):156-60. 
3. Barber SM, Rangel-Castilla L, Zhang YJ, Klucznik R, Diaz O. Mid- and long-term outcomes of carotid-cavernous fistula endovascular management with Onyx and n-BCA: experience of a single tertiary center. J Neurointerv Surg. 20015 Oct;7(10):762-9.

4. Chalouhi N, Dumont AS, Tjoumakaris S, Gonzalez LF, Bilyk JR, Randazzo C, et al. The superior ophthalmic vein approach for the treatment of carotid-cavernous fistulas: a novel technique using Onyx. Neurosurg Focus. 2012 May;32(5):E13.

5. Cheng KM, Chan CM, Cheung YL. Transvenous embolisation of dural carotid-cavernous fistulas by multiple venous routes: a series of 27 cases. Acta Neurochir (Wien). 2003 Jan;145(1):17-29.

6. Cheung N, McNab AA. Venous anatomy of the orbit. Invest Ophthalmol Vis Sci. 2003 Mar;44(3):988-95.

7. de Castro-Afonso LH, Trivelato FP, Rezende MT, Ulhoa AC, Nakiri GS, Monsiqnore LM, et al. Transvenous embolization of dural carotid cavernous fistulas: the role of liquid embolic agents in association with coils on patient outcomes. J Neurointerv Surg. 2018 May;10(5):461-462.

8. Elhammady MS, Wolfe SQ, Farhat H, Moftakhar R,
Aziz-Sultan MA. Onyx embolization of carotid-cavernous fistulas. J Neurosurg. 2010 Mar;112(3):589-94.

9. Gemmete JJ, Ansari SA, Gandhi DM. Endovascular techniques for treatment of carotid-cavernous fistula. J Neuroophthalmol. 2009 Mar;29(1):62-71.

10. Jahan R, Gobin YP, Glenn B, Duckwiler GR, Viñuela F. Transvenous embolization of a dural arteriovenous fistula of the cavernous sinus through the contralateral pterygoid plexus. Neuroradiology. 1998 Mar;40(3):189-93.

11. Komiyama M, Morikawa K, Fu Y, Yagura H, Yasui T, Baba M. Indirect carotid-cavernous fistula: transvenous embolization from the external jugular vein using a superior ophthalmic vein approach. A case report. Surg Neurol. 1990 Jan;33(1):57-63.

12. Luo CB, Chang FC, Teng MM, Ting TW. Anatomic variation of facial vein in carotid-cavernous fistula and trans-facial vein embolization. World Neurosurg. 2015 Jul;84(1):90-6.

13. Mounayer C, Piotin M, Spelle L, Moret J. Superior petrosal sinus catheterization for transvenous embolization of a dural carotid cavernous sinus fistula. AJNR Am J Neuroradiol. 2002 Aug;23(7):1153-5. 